\title{
Prosocial Motivation and Blood Donations: A Survey of the Empirical Literature
}

\author{
Lorenz Goette $^{\mathrm{a}} \quad$ Alois Stutzer $^{\mathrm{b}} \quad$ Beat M. Frey ${ }^{\mathrm{c}}$ \\ a Département of Economics, University of Lausanne, \\ ${ }^{\mathrm{b}}$ Department of Business and Economics, University of Basel, \\ ${ }^{c}$ Blood Transfusion Service SRC, Schlieren-Zürich, Switzerland
}

\section{Keywords}

Blood donation - Donors - Prosocial motivations . Incentives

\section{Summary}

Recent shortages in the supply of blood donations have renewed the interest in how blood donations can be increased temporarily. We survey the evidence on the role of financial and other incentives in eliciting blood donations among donors who are normally willing to donate pro bono. We present the predictions from different empirical/psychological-based theories, with some predicting that incentives are effective while others predict that incentives may undermine prosocial motivation. The evidence suggests that incentives work relatively well in settings in which donors are relatively anonymous, but evidence indicates also that when image concerns become important, incentives may be counterproductive as donors do not want to be seen as greedy.

\section{Introduction}

Maintaining a motivated group of individuals that are willing to donate blood is a key aspect of any blood donation service. Since blood donations are based in large parts on voluntary donations, the question arises what motivates those individuals that are willing to donate blood and how their motivation can best be managed and enhanced. In particular, blood donation services are often confronted with temporary fluctuations in demand for whole blood donations. How can blood donation services cope with such fluctuations in demand?

\author{
Schlüsselwörter \\ Blutspende - Spender · Prosoziale Motivationen . \\ Anreize
}

\section{Zusammenfassung}

Versorgungsknappheiten mit Bluttransfusionen haben ein neues Interesse an der Frage geweckt, wie kurzfristig mehr Blutspenden hervorgerufen werden können. In dieser Arbeit geben wir einen Überblick über die Evidenz zur Rolle von finanziellen und anderen Belohnungen. Wir diskutieren die verschiedenen theoretischen Ansätze. Einige Theorien legen positive Effekte von Belohnungen auf Blutspenden nahe, während andere einen negativen Effekt auf die Spendermotivation vorhersagen. Die Evidenz deutet auf positive Effekte hin, insbesondere wenn Blutspenden relativ anonym stattfinden. Die Evidenz deutet jedoch auch auf negative Effekte auf die Spendermotivation hin, wenn es der Umwelt bekannt ist, dass Blutspenden belohnt werden.

One possibility is to try and extract more donations from a given pool of donors. Economic theories of behavior suggest that one way to achieve this is to provide donors with an incentive to donate. However, this proposition is fiercely disputed in other areas of social science. As we explain in more detail, evidence suggests that, under certain conditions, incentives can interfere with the innate motivation to behave prosocially. This effect can be so strong that incentives may actually reduce the prosocial activity. Whether such an effect occurs, however, is an empirical question. The aim of this paper is to organize this discussion around the three dominant

\section{KARGER}

Fax +497614520714

Information@Karger.de

www.karger.com (c) 2010 S. Karger GmbH, Freiburg

Accessible online at:

www.karger.com/tmh 
theoretical frameworks, to discuss the evidence for the underlying assumptions, and to assess the evidence directly relevant for blood donations.

\section{Do Incentives Crowd Out Intrinsic Motivation?}

Different disciplines in the social sciences have sharply different views of the role of price incentives in motivating prosocial behaviors. The aim of this section is to present the different theories of how incentives affect prosocial activities and motivation. For each section, we provide a discussion of the evidence pertaining to the psychological mechanisms and then describe the evidence directly related to blood donations.

\section{The Economic View of Incentives}

Economists stress that incentives can help increase blood donations much like incentives can facilitate other activities. Individuals may care about prosocial activities for their own sake, such as donating to a charitable cause or donating blood, but the economic model emphasizes that costs and benefits also matter: the model assumes that, besides other goals, individuals also care about their material wellbeing. Thus, any activity that is rewarded more highly, will be followed more likely. While incentives alone certainly do not motivate blood donations, they may help to tip the balance to donate blood by somewhat lowering its costs.

The view that incentives can sometimes increase prosocial activities is not without empirical merit, in particular when it comes to charitable donations. For example, a recent study [1] examine the impact of matching on charitable donations. Matching refers to the promise to match every dollar the individual donates by a factor of $x$. Thus, the effective price of a donation becomes cheaper for the individual, and consequently he/she should donate more. Evidence shows indeed a positive impact of matching on the likelihood to donate money. Another study [2] examines the impact of chance to win a prize on donations. In a randomized field experiment, some households were offered the chance to win a monetary prize if they donated money while others served as a control group and were not offered any money. Again, offering the prize raised charitable contributions.

\section{Crowding Out of Intrinsic Motivation}

Since the early 1970s, the general view that incentives elicit a higher level of activity has been scrutinized. In particular, psychologists have examined tasks for which individuals in most cases display a motivation to perform them even when they are not paid, mostly because they are interesting by themselves. The basic argument is that paying individuals for such tasks undermines or even destroys their intrinsic motivation in the task [3, 4]. Various psychological mechanisms have been suggested that may lead to the undermining of intrinsic motivation: Individuals may feel 'overjustified' and replace the intrinsic motivation with the material motivation. Individuals may also perceive the use of payments as controlling, and it may be this aspect that undermines the intrinsic motivation in the task.

Importantly, the theory makes no clear prediction as to whether the use of incentives increases or decreases the level of activity when incentives are used. The prediction is that the intrinsic motivation is destroyed, but not that the net effect is necessarily negative. Testing this prediction has proven to be tricky. The typical experiment consists of three stages: in the initial stage, a subject is invited to a study and has to wait for a while. There is a Rubik's cube on the table, and it is measured for how long the subject plays with the cube. In the second stage, the subject is told that she will be paid based on her performance in the Rubik's cube. Finally, in the third stage, the subject is left alone again, and it is measured how much the subject plays with the cube. If the subject plays less with the cube in the third stage than in the first, this is taken as evidence that paying the subject has reduced her intrinsic interest in playing with the cube. Many studies show that activity in the last phase is significantly lower than in the first when incentives are used in between. However, critics have pointed out that the problem with this test is that it does not hold the level of activity constant. Most people perform the task significantly more intensely when they are paid than the control group. The number of studies has grown so large that we directly refer readers to meta-analyses (see [5] for the most recent survey of the results). There is a fair amount of discord between different teams of researchers [6]. Thus, the lower activity may just reflect temporarily being fed up with the task. More convincingly, other studies have separated phases 2 and 3 of the experiment by a longer time distance. In support of the view that intrinsic motivation is being crowded out, interest in the task is even lower several weeks after incentive have been used (see table 7 in [5]). Furthermore, one could argue that it was the receipt of a reward, and not the contingency of the reward on the activity, that changed the motivation. However, experiments in which participants are not told that they may receive a reward, but then receive one at the end of phase 2 anyway, do not display a decrease in the activity in phase 3, showing that it is not the payment of money, but the contingency on the reward that undermines the motivation (see table 5 in [5]). Thus, overall, there is clear evidence that monetary rewards can undermine the intrinsic motivation individuals have placed in a task.

\section{Evidence on Blood Donations}

The evidence from psychology has lead researchers to speculate that a similar mechanism may be present if one paid individuals to donate blood, and even if the payment was just temporary. Titmuss' famous book alludes to this possibility [7], even though no randomized study had been conducted at that time. The first study was conducted by Upton [8]. He 
called individuals and asked them to sign up for a blood donation. The treatment group was promised compensation if they donated blood while the control group was not. The dependent variable of the study was to then measure whether a donor follows through on his pledge and donates blood. Upton [8] found that of the individuals who had donated blood before presumably a measure of higher motivation to donate blood - those who were promised compensation were less likely to follow through and show up for donate, while he observed the opposite pattern for individuals who never donated before. But, while suggestive of crowding-out of motivation, a failure to properly randomize makes it difficult to interpret this result. Upton [8] already announced the compensation when he recruited individuals to sign up, thus potentially changing the composition of donors in the treatment and the control group. Any differences in behavior between the two groups can thus not be interpreted as the causal effect of incentives on behavior. An experiment that would have avoided this problem would have recruited all donors without the promise of compensation. One could then randomly select half of the participants, call them again, and tell them that, if they follow through on their pledge, they would receive a reward. This way, the assignment of the reward occurs after the pledge has been made and can longer affect the pledge.

However, more recently, evidence has been accumulating on the effects of incentives on blood donations. Most studies used a design in which the use of incentives was explicitly randomized. The foremost interest of the studies was to examine whether incentives would lead to more blood donations. Ferrari et al. [9] had offered coupons that could be redeemed for merchandise and found that it strongly increased the propensity to donate blood in their sample of college students. Researchers have used a variety of incentives. Another study [10] used T-shirts as incentives in a randomized study. However, they found no significant impact on the propensity to donate blood. We [11] conducted an experiment with blood donors of the Red Cross blood donation service in the canton of Zurich. During a 3-month period, some of the blood donors had been offered a lottery ticket (which would cost about USD 5.- in stores) if they donate blood in one of the Red Cross donation centers, while others had been invited as usual - without a reward. We found a $5 \%$ increase in the proportion of donations if individuals were promised a lottery ticket. We also found a strong interaction of the treatment with the individual's inherent propensity to donate. The entire effect of the lottery ticket came from donors who have a baseline rate of about $30 \%$ to donate blood: The lottery ticket increased their donations by almost $9 \%$, a large and significant increase. By contrast, individuals with a higher baseline probability to donate (approximately 75\%) showed absolutely no reaction to the lottery ticket. It should be noticed that this cannot be explained by a mechanical ceiling effect. All donors who were invited were prescreened to donate blood, and the baseline donation rates were low enough so that this group could have increased their propensity to donate in response to the lottery ticket if they had wanted to, like the group of generally less motivated donors. Thus, they find sizeable reactions to the lottery ticket, in particular in the subgroup of donors that normally do not donate blood very often. However, so far, the key prediction of the crowding-out hypothesis has not been tested. If donors are invited again and the incentives are no longer used, does this reduce the propensity to donate blood? Our subjects were subsequently invited according to the normal procedures, which allowed us to examine this point [11]. We followed the donors up to 18 months after the termination of the experiment, but find no effect on subsequent donations. If anything, individuals who had previously received a lottery ticket are slightly more likely to donate blood in the 18 months subsequent to the study, but the effect is not significant. Furthermore, no interaction with donor type is observed in the 18 months after the experiment. Thus, to this date, there is no evidence of crowding out of motivation for blood donations when incentives are used.

These generally positive results of incentives on blood donations are also surprising given the results from surveys among blood donors. Glynn et al. [12] asked donors in a survey how different types of gifts and incentives would impact their motivation to donate. The response was mixed: some say they would donate more while others say they would donate less. They also asked them about the type of incentives to be used. The emerging pattern was that the more the incentive used resembles money, the less it was accepted. Similar results were obtained for Europe by Lacetera and Macis [13]. The category that was most accepted [12] were incentives that were somehow related to health. Goette et al. [14] reported the results from another treatment of the Zurich experiment: in this treatment, individuals had been offered a free cholesterol test if they show up to donate blood. The offer of the test had no effect on donations. The authors also searched in various subgroups, cutting the sample by age, motivation and gender, but they fail to detect any reaction. Thus, in contrast to the survey evidence, offering a reward such as a health test appeared to be ineffective, while in the same sample, the lottery ticket increased donations. We find it difficult to explain why survey results and evidence from randomized trials point in so different directions. In contrast to surveys, experiments have the advantage of measuring actual preferences, rather than stated preferences as in surveys. The discrepancy in results makes it clear that caution has to be applied to interpreting results from surveys.

To summarize, the results reviewed in this section showed no negative effects of incentives on blood donations when the studies were properly randomized. It is important, however, to keep in mind the scope of these studies. An important concern is that financial incentives may attract donors with worse risk factors [7]. Keeping in mind that all studies so far have only examined short-run interventions, there is so far no evidence that incentives attract donors with worse health charac- 
teristics among a pool of previous donors [11]. However, no randomized evaluation exists to examine the long-run effects. Most of the studies were conducted with prescreened blood donors, and donations took place in the relative privacy of donation centers. They are consistent with the results from field experiments examining the effect of incentives on charitable donations, where positive incentive effects are found as well. Overall, the results provide no support for the predictions from theories of motivational crowding [15]. They provide moderate support for the view that incentives help to tip the balance in favor of more blood donations. However, several studies also found no effects, and this type of heterogeneity remains to be explained.

\section{Incentives and Image Concerns in Blood Donations}

Thus, while the evidence from the previous section comes from studies in which donors donated blood in the relative privacy of donation centers, this is often not the case. An important fraction of blood donations is collected in blood drives, which often have a strong social component to them. Participation is far from anonymous as, depending on the setting, one's co-workers, neighbors or friends may know whether or not one donated blood. Recent research in economics has identified such situations as an additional constraint on the effectiveness of incentives.

\section{Image Concerns and Prosocial Motivations}

Recent theoretical models [16] argue that individuals also care about what others think of them. In particular, individuals want to be seen as prosocial and do not want to be seen as driven by monetary concerns. Under these circumstances, incentives may reduce prosocial activities because they make individuals look greedy. Consider a situation in which blood donations are not rewarded. Those individuals who care enough about blood donations will be willing donate anyway. Because they donate blood, they are also recognized as such and enjoy image rewards. However, consider what happens when incentives are introduced. Incentives make it attractive for less motivated individuals to donate blood as well. Worse yet, they may attract individuals that simply do it for the money, thus further lowering the image rewards from donating blood. Thus, incentives may deter individuals who previously had donated blood. In a clever experiment, Ariely et al. [17] tested this mechanism. Subjects had the opportunity to generate donations for charitable causes by performing pairs of clicks on the keyboard of their computer. There were two treatment variables: financial incentives and whether or not the donation was public. In the public condition, subjects had to stand up one by one at the end of the experiment and announce how often they clicked and whether they were paid. The results first showed that image concerns were an important determinant of charitable giving: subjects in the public condition clearly clicked more than subjects in the private condition [see also 18]. Thus, the prospect that others will found out how much effort they put into charitable donations (the number of clicks) motivated subjects to generate more donations. The results also showed that image concerns affect the effectiveness of incentives: while in the private condition, incentives clearly raised the effort of the subjects, this was not the case in the public condition. If anything, incentives lowered the effort put into generating donations, in line with the predictions from the model [16]. That incentives undermine prosocial motivations in public settings is also consistent with the results from several studies [19]. All the available evidence suggests that small financial rewards undermine prosocial motivations only in a situation in which effort choices and the fact that effort was or was not rewarded were public.

\section{Evidence on Blood Donations}

A clever study aimed at testing the relevance of this mechanism directly in the context of blood donations [20]. The authors conducted an experiment with three conditions. In the baseline conditions, participants were asked whether or not they want to donate blood. There was a bus waiting for them, taking them directly to the nearest donation center. Therefore, in this treatment, as in the others, the decision to donate blood was public, as it was very clear who gets into the bus and who does not. In the first treatment, subjects were offered money if they donate blood. In the second treatment, subjects were offered the possibility to donate the money to a charitable organization. The difference between the first and the second treatment was that the second treatment offered an opportunity to signal that one was not doing it for the money, by giving the money away. Therefore, the prediction was that incentives should be more effective in the second treatment than in the first. The results were somewhat muddled, but generally supportive of this mechanism: overall, there were no significant differences across the three conditions. However, the authors found a strong interaction with gender. While the propensity to donate of men was unaffected by any of the treatments, women did react strongly to the treatments: donation rates were markedly lower when females were offered incentives. However, the effect can be avoided when they were given the possibility to donate the money. The fact that the effect only showed up in a subsample was somewhat problematic. Other studies testing for image motivation [17] did not find a similar interaction with gender, though survey evidence was consistent with it [21]. It implies that women are more sensitive to image rewards, which could be tested in other settings.

One study [21] examined correlational evidence from a large number of local blood drives in the USA. Some of these blood drives offer incentives such as T-shirts, or gift cards for local stores. The evidence reveals that drives that offer gifts attract more donors. However, one has to be very careful in interpreting these results: the incentives to donors are not 
randomized across drives, but allocated by district managers to particular drives. Furthermore, the data do not allow the identification of the number of donors that were invited to a drive. Thus, if drives with a larger potential donor base are more likely to use incentives, this would bias the estimation results towards finding a positive correlation between incentives and donations.

To summarize, the evidence with regard to the importance of image concerns in blood donations is mixed. While experiments show that image concerns are important in other domains of prosocial behavior, clean evidence on blood donations is still lacking. Studies that examine this issue either show ambiguous results [20] or are not properly randomized [21].

\section{Concluding Remarks}

This paper reviews empirical studies that examine the effectiveness of incentives to (temporarily) increase blood donations. The evidence shows that when the donations are made in the relative anonymity of donation centers, incentives are effective in generating more donations [9, 11, 14]. Furthermore, the evidence also suggests that a very simple form of incentives - lottery tickets or gift vouchers - have a significant impact, in particular on donors who in general have a lower propensity to donate. The evidence we review also suggests that other incentives such as offering a cholesterol test [14] or T-shirts [10] do not lead to an increase in donations. This evidence is in line with evidence from other forms of prosocial behaviors, such as charitable donations $[1,2]$. The evidence reviewed here lends no support to the conjecture that the crowding effects of incentives found in intrinsically interesting tasks [5] carry over to prosocial activities. Psychological theories of intrinsic motivation raise the possibility that individuals' motivation will be permanently undermined by the use of incentives, but the one study that can track blood donors over 18 months after incentives have been used showed no such effect [11].

Thus, while the evidence points to largely positive (or zero) effects of incentives when donations take place in relatively anonymous donation centers, much less is known about the effect of incentives in more public blood drives. In such drives, concerns by individuals to look greedy or cheap if they donate when incentives are used are heightened, and theory predicts potentially negative effects of incentives [16]. The mechanisms have been shown to be in place for other forms of prosocial behavior when the activity is publicly observed [17-19]. Evidence also provides some evidence that this is relevant for blood donations [20], though the results are still inconclusive and contradictory [21]. More studies are needed to address this issue, and caution should be applied in using incentives in more public settings until the results become clearer.

While the focus of this paper was to examine the potential role of incentives in overcoming temporary shortages, one can also ask whether this may be a smart strategy in the long-run. In this case, the concerns are heightened by the potential that paying for blood donations may attract donors with worse health risk factors. But while anecdotes about the long-run effects abound [22, 23], we are not aware of any credibly randomized study to address this question. In fact, little is known about the long-run effects on using incentives also in other domains of prosocial behavior. However, efforts may be misplaced to explore the effectiveness of incentives in this case. For other dimensions of prosocial behavior, other mechanisms have been shown to be effective, making them a more natural candidate to examine their role in blood donations. For example, consistent with the results that individuals care about their image, results also show that individuals adjust their prosocial behavior in response to what others do: if others contribute more, so do they [24, 25]. Such mechanisms have also proved powerful in different areas such as effort put into work [26] or schooling choices for children [27]. Several possible policies could take advantage of this mechanism in increasing blood donations in the long run. After considerable effort has been put into examining incentives, it may be time to turn attention to exploring the role of other motivations in blood donations. Such a venture poses new challenges to a randomized evaluation, but many techniques to estimate the effects of others' behavior on one's own have been developed.

\section{Disclosure}

The authors declared no conflict of interest.

\section{References}

1 Karlan D, List JA: Does price matter in charitable giving? Evidence from a large-scale natural field experiment. Am Econ Rev 2007;97:1774-1773.

2 Landry C, Lange A, List J, Price M, Rupp N: Towards an understanding of the economics of charity: evidence from a field experiment. Quart J Econ 2006;121:747-782.

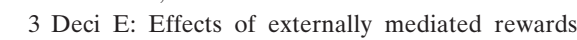
on intrinsic motivation. J Personality Soc Psychol 1971;18:105-115.
4 Lepper M R, Greene,D, Nisbett RE: Untermining children's intrinsic interest with extrinsic rewards: a test of the overjustification hypothesis. J Personality Soc Psychol 1973;28:129-137.

5 Deci EL, Koestner R, Ryan RM: A meta-analytic review of experiments examining the effects of extrinsic rewards on intrinsic motivation. Psychol Bull 1999;125:627-668.

6 Eisenberger R, Cameron J: Detrimental effects of reward: reality or myth? Am Psychol 1996;51:676-679.
7 Titmuss RM: The Gift Relationship: From Human Blood to Social Policy. New York, Random House, 1971.

8 Upton WE: Altruism, Attribution, and Intrinsic Motivation in the Recruitment of Blood Donors. Dissertation, Cornell University, 1973.

9 Ferrari JR, Barone RC, Jason LA, Rose T: The use of incentives to increase blood donations. J Soc Psychol 2001;125:791-793. 
10 Reich P, Roberts P, Laabs N, Chinn A, McEvoy P, Hirschler N, Murphy EL: A randomized trial of blood donor recruitment strategies. Transfusion 2006;46:1090-1096.

11 Goette LF, Stutzer A: Blood donations and incentives: evidence from a field experiment (July 2008). IZA Working Paper No. 3580. Available at SSRN: http://ssrn.com/abstract $=1158977$ or doi:10.1111/ j.0042-7092.2007.00700.x.

12 Glynn SA, Williams AE, Nass CC, Bethel J, Kessler D, Scott EP, Fridey J, Kleinman SH, Schreiber GB: Attitudes toward blood donation incentives in the United States: implication for donor recruitment. Transfusion 2003;43:7-16.

13 Lacetera N, Macis M, Slonim R: Will There Be Blood? Incentives and Substitution Effects in ProSocial Behavior. IZA Discussion Papers 4567, Institute for the Study of Labor (IZA), 2009

14 Goette L, Stutzer A, Yavuzcan G, Frey B: Free cholesterol testing as a motivation device in blood donations: evidence from field experiments Transfusion 2009;49:524-531.

15 Deci EL, Ryan RM: Intrinsic Motivation and SelfDetermination in Human Behavior. New York, Plenum Press, 1985.

16 Bénabou R, Tirole J: Incentives and prosocial behavior. Am Econ Rev 2006;96:1652-1678.

17 Ariely D, Bracha A, Meier S: Doing good or doing well? Image motivation and monetary incentives in behaving prosocially. Am Econ Rev 2009;99:544555.

18 Linardi S, McConnell MA: Volunteering and Image Concerns. Working Papers 1282, California Institute of Technology, Division of the Humanities and Social Sciences, 2008.

19 Gneezy U, Rustichini A: Pay enough or don’t pay at all. Quart J Econ 2000;115:791-810.

20 Mellström C, Johannesson M: Crowding out in blood donation: was Timuss right? J Eur Econ Assoc 2008;6:845-863.

21 Lacetera N; Macis M: Do All Material Incentives for Prosocial Activities Backfire? The Response to Cash and Non-Cash Incentives for Blood Donations. IZA Discussion Papers 4458, Institute for the Study of Labor (IZA), 2009.

22 Fontaine P: Blood, politics, and social science Richard Titmuss and the Institute of Economic Affairs, 1957-1973. Isis 2002;93:401-434.

23 Shearmur J: In defense of the commercial provision of blood: reactions to voluntarism in the United States national blood policy in the early 1970s. J Value Inquiry 2006;40:279-295.

24 Frey BS, Meier S: Social comparisons and prosocial behavior: testing 'conditional cooperation' in a field experiment. Am Econ Rev 2004;94:17171722.

25 Fischbacher U, Gaechter S, Fehr E: Are people conditionally cooperative? Evidence from a public goods experiment. Econ Lett 2001;71:397-404

26 Mas A, Moretti E: Peers at work. Am Econ Rev 2009;99:112-45.

27 Lalive R, Cattaneo MA: Social interactions and schooling decisions. Rev Econ Stat 2009;91:457-477. 